\title{
Structural insights into the interaction of the nuclear exosome helicase Mtr4 with the preribosomal protein Nop53
}

\author{
SEBASTIAN FALK, ${ }^{1}$ JAN-NIKLAS TANTS, ${ }^{2,3}$ JERÔME BASQUIN, ${ }^{1}$ MATTHIAS THOMS, ${ }^{4}$ ED HURT, ${ }^{4}$ \\ MICHAEL SATTLER, ${ }^{2,3}$ and ELENA CONTI ${ }^{1}$ \\ ${ }^{1}$ Max-Planck-Institute of Biochemistry, Department of Structural Cell Biology, D-82152 Martinsried, Germany \\ ${ }^{2}$ Center for Integrated Protein Science Munich at Chair of Biomolecular NMR Spectroscopy, Department Chemie, Technische Universität München, \\ 85748 Garching, Germany \\ ${ }^{3}$ Institute of Structural Biology, Helmholtz Zentrum München, 85764 Neuherberg, Germany \\ ${ }^{4}$ Heidelberg University Biochemistry Center (BZH), INF 328, D-69120 Heidelberg, Germany
}

\begin{abstract}
The nuclear exosome and the associated RNA helicase Mtr4 participate in the processing of several ribonucleoprotein particles (RNP), including the maturation of the large ribosomal subunit (60S). S. cerevisiae Mtr4 interacts directly with Nop53, a ribosomal biogenesis factor present in late pre-60S particles containing precursors of the 5.8S rRNA. The Mtr4-Nop53 interaction plays a pivotal role in the maturation of the 5.8S rRNA, providing a physical link between the nuclear exosome and the pre-60S RNP. An analogous interaction between Mtr4 and another ribosome biogenesis factor, Utp18, directs the exosome to an earlier preribosomal particle. Nop53 and Utp18 contain a similar Mtr4-binding motif known as the arch-interacting motif (AIM). Here, we report the $3.2 \AA$ resolution crystal structure of $S$. cerevisiae Mtr4 bound to the interacting region of Nop53, revealing how the KOW domain of the helicase recognizes the AIM sequence of Nop53 with a network of hydrophobic and electrostatic interactions. The AIM-interacting residues are conserved in Mtr4 and are not present in the related cytoplasmic helicase Ski2, rationalizing the specificity and versatility of Mtr4 in the recognition of different AIM-containing proteins. Using nuclear magnetic resonance (NMR), we show that the KOW domain of Mtr4 can simultaneously bind an AIM-containing protein and a structured RNA at adjacent surfaces, suggesting how it can dock onto RNPs. The KOW domains of exosomeassociated helicases thus appear to have evolved from the KOW domains of ribosomal proteins and to function as RNPbinding modules in the context of the nuclear exosome.
\end{abstract}

Keywords: RNA exosome; DExH helicase; ribosome biogenesis; FRH

\section{INTRODUCTION}

The exosome is a conserved RNA-degrading complex that catalyzes the decay and processing of a large number of transcripts in both the nucleus and the cytoplasm of eukaryotic cells (Mitchell et al. 1997; Chlebowski et al. 2013). In the cytoplasm, the exosome participates in mRNA turnover and in surveillance pathways activated when ribosomes stall on aberrant mRNAs (Schaeffer et al. 2011; Graille and Séraphin 2012; Shoemaker and Green 2012). In the nucleus, exosome-mediated degradation also eliminates unnecessary and defective RNAs (such as tRNAs or transcripts generated from pervasive transcription) and is involved in the biogenesis of structured RNAs [such as rRNAs and sn(o)RNAs] (Butler and Mitchell 2011; Sloan et al. 2012; Kilchert et al. 2016). The processing of rRNA is indeed a major function of this complex, which acts both at early nucleolar stages and at late nucleoplasmic stages of rRNA biogenesis

Corresponding author: conti@biochem.mpg.de

Article is online at http://www.rnajournal.org/cgi/doi/10.1261/rna.062901. 117. Freely available online through the RNA Open Access option.
(Thomson et al. 2013; Henras et al. 2015; Turowski and Tollervey 2015). In the nucleolus, the yeast exosome degrades the $5^{\prime}$ external transcribed spacer ( $5^{\prime}$ ETS), a byproduct in the formation of the small ribosomal subunit (Allmang et al. 2000). In the nucleoplasm, the exosome trims the second internal transcribed spacer (ITS2) and generates a precursor of the 5.8S rRNA, an integral part of the large ribosomal subunit that is exported to the cytoplasm (Briggs 1998; Allmang et al. 1999; Nissan et al. 2002). Exosome-mediated maturation of the 5.8S rRNA is an important step before the pre-60S subunit is exported to the cytoplasm (Thomson and Tollervey 2010). This exosome-mediated process is also conserved in human cells (Schilders et al. 2007).

The nuclear and cytoplasmic forms of the yeast exosome contain different cofactors assembled around the same processive ribonuclease core (the 10-subunit Exo-10 complex) (Makino et al. 2013b; Zinder and Lima 2017). Cytoplasmic Exo-10 is constitutively bound to the adaptor protein Ski7,

(c) 2017 Falk et al. This article, published in $R N A$, is available under a Creative Commons License (Attribution-NonCommercial 4.0 International), as described at http://creativecommons.org/licenses/by-nc/4.0/. 

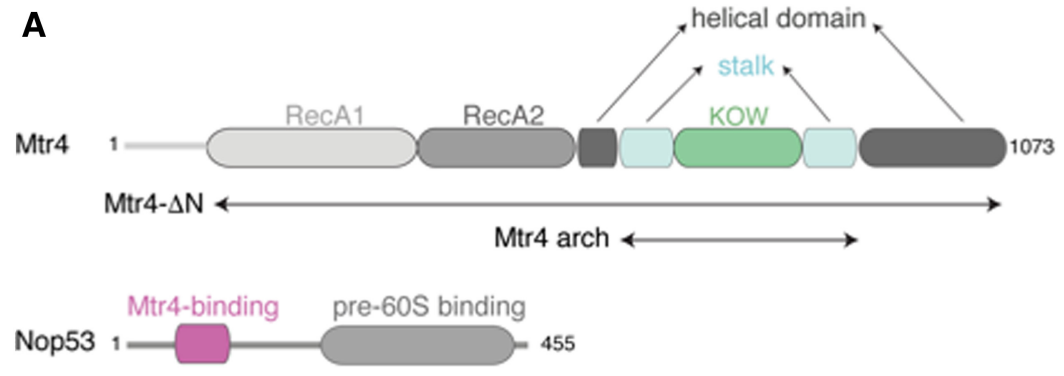

B

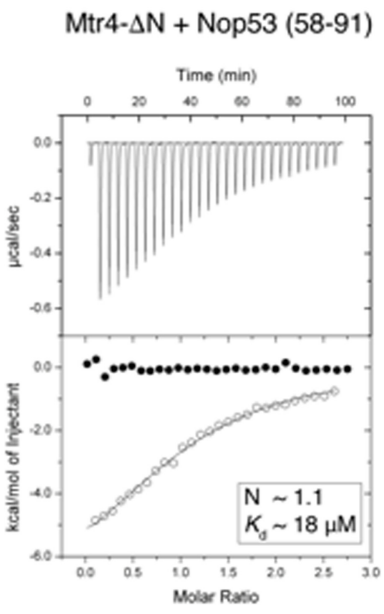

FIGURE 1. Biophysical characterization of Mtr4 binding to AIM-containing proteins. $(A)$ Schematic representation of the domain structure of yeast Mtr4 and Nop53. Predicted unstructured regions are represented as gray lines. The Nop53 fragment identified by proteolysis contains the arch-interacting motif (AIM) identified by Thoms et al. (2015). (B) ITC experiments of Mtr4$\Delta \mathrm{N}$ with Nop $53_{\text {prot }}$ and Utp $18_{\text {prot }}$. The open circles show the titration of Nop $53_{\text {prot }} / \mathrm{Utp} 18_{\text {prot }}$ into the Mtr $4-\Delta \mathrm{N}$ containing cell. The filled circles show the control where Nop53 prot $/ \mathrm{Utp} 18_{\text {prot }}$ were titrated into buffer. In each inset is the number of calculated binding sites $(N)$, and dissociation constants $\left(K_{\mathrm{d}}\right)$ are shown.

which in turn recruits the Ski2-Ski3-Ski8 helicase complex (Brown et al. 2000; Araki et al. 2001; Halbach et al. 2013; Kowalinski et al. 2016). Nuclear Exo-10 is constitutively bound to Rrp6-Rrp47 and together with Mpp6 recruits the Mtr4 helicase (Schilders et al. 2005; Makino et al. 2013a, 2015; Schuch et al. 2014; Wasmuth et al. 2014; Zinder et al. 2016). These cofactors are conserved from yeast to human and are required for the specific functions of the exosome complex in either subcellular compartment (Sloan et al. 2012; Chlebowski et al. 2013; Kowalinski et al. 2016). In particular, the Mtr4 and Ski2 helicases are believed to remodel RNA substrates and target them to exosome-mediated degradation (Johnson and Jackson 2013). The nuclear and cytoplasmic exosome-associated helicases share a similar overall architecture (Johnson and Jackson 2013; Ozgur et al. 2015). The $\mathrm{N}$-terminal regions of Mtr4 and Ski2 are intrinsically unstructured and interact with other cofactors (Rrp6-Rrp47 and Ski3, respectively) in either a transient or stable manner (Halbach et al. 2013; Schuch et al. 2014). The helicase regions contain the DExH core typical of processive $3^{\prime}-5^{\prime}$ RNA-dependent ATPases as well as a specialized insertion generally known as the "arch" domain for its char- acteristic curved structure (Jackson et al. 2010; Weir et al. 2010; Halbach et al. 2012; Johnson and Jackson 2013). In vivo, the arch of Mtr4 is required for 5.8S rRNA maturation and 5' ETS degradation (Jackson et al. 2010; Klauer and van Hoof 2012) while the arch of Ski2 promotes the cytoplasmic functions of the exosome (Klauer and van Hoof 2012).

The Mtr4 arch culminates with a small globular fold with structural similarity to the KOW (Kyrpides-Ouzounis-Woese) domain found in several ribosomal proteins (Kyrpides et al. 1996; Weir et al. 2010). Although no structural information is currently available, biochemical data have shown that the KOW domain of Mtr4 can bind structured RNAs (Weir et al. 2010; Li et al. 2016) and can bind the ribosome biogenesis factors Nop53 and Utp18 (Thoms et al. 2015). Yeast Utp18 is an early-acting factor involved in the processing of the $5^{\prime}$ ETS from the $90 \mathrm{~S}$ preribosomal particle (Bernstein et al. 2004). Conversely, Nop53 is a conserved late-acting factor in the maturation of the pre-60S subunit and is required for the trimming of the 5.8S rRNA (Granato et al. 2005, 2008; Thomson and Tollervey 2005). Mechanistically, the interactions of Mtr4 with Nop53 and Utp18 are believed to direct the nuclear exosome to specific preribosomal RNP substrates (Thoms et al. 2015).

Nop53 binds the pre-60S subunit with the C-terminal domain (Wu et al. 2016) and binds Mtr4 with the $\mathrm{N}$-terminal domain, which contains a short linear sequence termed the arch-interacting motif (AIM) (Thoms et al. 2015). A similar Mtr4-binding sequence is present in Utp18 (Thoms et al. 2015). Biochemical data have shown that a negatively charged aspartate residue in the AIM sequence of Nop53/Utp18 and a positively charged arginine residue in the KOW domain of Mtr4 are crucial for the interaction (Thoms et al. 2015). However, this positively charged residue is highly conserved not only in Mtr4 but also in Ski2, which does not interact with Nop53. What is the basis for the Mtr4 specificity and versatility in binding AIM-containing proteins, and what is the interplay between protein and RNA binding? In this short Report, we addressed these questions using X-ray crystallography and nuclear magnetic resonance.

\section{RESULTS AND DISCUSSION}

We purified a fragment of S. cerevisiae Nop53 (residues 4899), which includes the AIM sequence (Thoms et al. 2015), 
and formed a complex with the arch domain of Mtr4. Limited proteolysis experiments on the complex allowed identifying a proteolytically stable segment of Nop53 encompassing residues 58-91 (Nop53 $3_{\text {prot }}$ ) (Fig. 1A; Supplemental Fig. 1). We measured the strength of the interaction with Mtr4 using isothermal titration calorimetry (ITC). Purified recombinant Nop5 $3_{\text {prot }}$ bound the helicase region of Mtr4 (Mtr4- $\Delta \mathrm{N}$ ) with a $K_{\mathrm{d}}$ of $\sim 18 \mu \mathrm{M}$ (Fig. 1B, left panel). The corresponding fragment of Utp18 containing residues 78110 (Utp18 prot) interacted with Mtr4- $\Delta \mathrm{N}$ with a similar $K_{\mathrm{d}}$ of $\sim 20 \mu \mathrm{M}$ (Fig. 1B, right panel). Mtr4- $\Delta \mathrm{N}$ in the presence of an excess of Nop $53_{\text {prot }}$ yielded diffracting crystals containing two copies of the complex in the asymmetric unit. The structure was solved by molecular replacement using individual domains of Mtr4 as search models (Jackson et al. 2010; Weir et al. 2010) and refined at $3.2 \AA$ resolution to $R_{\text {free }} 26.7 \%, R_{\text {factor }}$ of $21.0 \%$ and good stereochemistry (Supplemental Table 1). The two copies of the complex in the asymmetric unit are very similar, superposing with a root mean square deviation (rmsd) of $1.07 \AA$ over all $\mathrm{Ca}$ atoms. In each copy, the final model contains essentially the entire Mtr4- $\Delta \mathrm{N}$ molecule and residues 59-70 of Nop53, slightly longer than the previously identified AIM motif (residues 60-64 [Thoms et al. 2015]).

Mtr4- $\Delta \mathrm{N}$ has a similar overall structure in the Nop $53_{\text {prot }^{-}}$ bound complex when compared to the unbound state (Jackson et al. 2010; Weir et al. 2010). Briefly, the DExH core of Mtr4 is formed by two adjacent RecA domains juxtaposed to a helical domain (Fig. 2A). Inserted into the DExH helicase is a large protuberance, the arch, which hovers around the entrance of the helicase unwinding channel. The arch consists of a stalk region that is formed by two pairs of antiparallel $\alpha$-helices (helices $\alpha 1-\alpha 4$ and helices $\alpha 2-\alpha 3$ ) and ends in the small globular KOW domain (Fig. 2A; Weir et al. 2010). The Mtr4 KOW domain contains a fivestranded $\beta$-barrel flanked by two $\alpha$-helices. The short helix at the side of the barrel $(\alpha \mathrm{A})$ is directly connected to helix $\alpha 2$ of the stalk (Fig. $2 \mathrm{~A})$. The longer helix at the top $(\alpha \mathrm{B})$ is connected to the last strand $(\beta 5)$ of the barrel by an extended linker (residues 776-785, referred to as linker L1) and is connected to the helix $\alpha 3$ of the stalk by another extended linker (residues 801-818, referred to as linker L2) (Fig. 2A). In addition, the KOW domain contains two long loops that approach the DExH core: The $\beta 2-\beta 3$ loop (residues 700 715 ) contacts the helical domain while the $\beta 3-\beta 4$ loop (residues 724-758) points toward the RecA2 domain (Fig. 2A). Although the arch is involved in crystal contacts, its conformation is very similar to that observed in the structures of Mtr4 in isolation (Jackson et al. 2010; Weir et al. 2010), which had been crystallized in different space groups and with different lattice contacts. While a bent arch with the KOW domain resting on the DExH core might reflect an energetically favorable state, this domain can undergo conformational changes: In the Mtr4-Trf4-Air2 structure, for example, the arch is rotated about $35^{\circ}$ toward the RecA2 domain and in this conformation exclusively interacts with the RecA2 domain without contacting the helical domain (Falk et al. 2014).

Nop53 binds in an extended conformation at the top of the Mtr4 KOW domain (Fig. 2B; Supplemental Fig. 2A,B), with a similar overall path as we previously observed in a crystal lattice interaction in the structure of Mtr $4-\Delta N-T r f 4_{N}-A i r 2_{N}$ (Falk et al. 2014; Supplemental Fig. 2C-E). The ordered portion of Nop53 starts with the LFX $\phi D$ consensus of the AIM motif (Thoms et al. 2015). At the $\mathrm{N}$ terminus of the motif, Leu60 $0_{\mathrm{Nop} 53}$ contacts helix $\mathrm{aB}$ of the KOW domain. The motif continues as a $\beta$-strand that packs in an antiparallel fashion against the $\mathrm{C}$-terminal part of the $\beta 5$ strand, which in turn packs in an antiparallel fashion against the first $\beta$-strand of the KOW $\beta$-barrel. On one side of the Nop53 $\beta$-strand, two hydrophobic side chains (Phe61 $1_{\mathrm{Nop} 53}$ and Val63 ${ }_{\mathrm{Nop} 53}$ ) engage in van der Waals interaction with an apolar patch of the KOW domain formed by helix $\alpha \mathrm{B}$ (Val797 ${ }_{\mathrm{Mtr} 4}$ ), $\beta 5$ (Leu773 $_{\mathrm{Mtr} 4}$, Leu775 ${ }_{\mathrm{Mtr} 4}$ ), and linker L2 (Phe801 $1_{\mathrm{Mtr} 4}$, Ile805 ${ }_{\mathrm{Mtr} 4}$, Pro810 ${ }_{\mathrm{Mtr} 4}$ ) (Fig. 2B). On the other side of the Nop53 $\beta$-strand, His62 $2_{\text {Nop53 }}$ wedges between the side chains of Arg774 $4_{\text {Mtr4 }}(\beta 5)$ and Tyr776 $6_{\text {Mtr4 }}$ (linker L1), while Asp64 ${ }_{\mathrm{Nop} 53}$ forms a bidentate salt-bridge interaction with the guanidinium groups of Arg774 $4_{\mathrm{Mtr} 4}$ (which is exposed on the surface of the KOW) and Arg678 ${ }_{\text {Mtr } 4}$ (most of which is embedded in the KOW hydrophobic core) (Fig. 2B). After the AIM motif, the Nop53 backbone bends and extends toward the KOW helix $\alpha \mathrm{A}$. In this segment, Val65 $5_{\text {Nop53 }}$ and Gly67 $7_{\text {Nop53 }}$ engage in van der Waals interactions with another apolar patch of the KOW domain formed by linker L2 (Pro806 ${ }_{\text {Mtr } 4}$, Leu808 ${ }_{\text {Mtr } 4}$, Met814 $4_{\text {Mtr } 4}$ ) and helix aA (Phe673 ${ }_{\text {Mtr } 4}$ ) (Fig. 2B).

The structural analysis rationalizes previous biochemical data showing the deleterious effects of mutation of either Asp64 $4_{\text {Nop53 }}$ or Arg678 ${ }_{\text {Mtr4 }}$ (Thoms et al. 2015) and also predicts an important role for Arg774 $4_{\mathrm{Mtr} 4}$. We generated two Mtr4 KOW mutants in the background of the Mtr4 short arch, containing the stalk helices $\alpha 2$ and $\alpha 3$ and the KOW domain. Both, the previously characterized R678A mutant and a reverse-charge substitution of Arg774 (R774E mutant) impaired Nop53 binding in pull-down assays (Fig. 2C). Interestingly, mutation of the corresponding arginine residue in the $N$. crassa Mtr4 ortholog, FRH, compromises the specific function of this protein in the Ascomycota circadian clock (Shi et al. 2010). In general, while the Nop53-binding residues are highly conserved across Mtr4 species, they have diverged in the related cytoplasmic helicase Ski2, which contains a similar domain but does not bind Nop53 (Fig. 2D; Halbach et al. 2012; Thoms et al. 2015). The only Nop53-interacting residue present in both Mtr4 and Ski2 (Arg678 ${ }_{\text {Mtr4 }}$ and the corresponding $\operatorname{Arg} 903_{\text {Ski2 }}$ ) is likely conserved for structural reasons as it forms part of the KOW domain hydrophobic core. Conversely, the Mtr4-binding residues are conserved in Nop53 and in Utp18. 

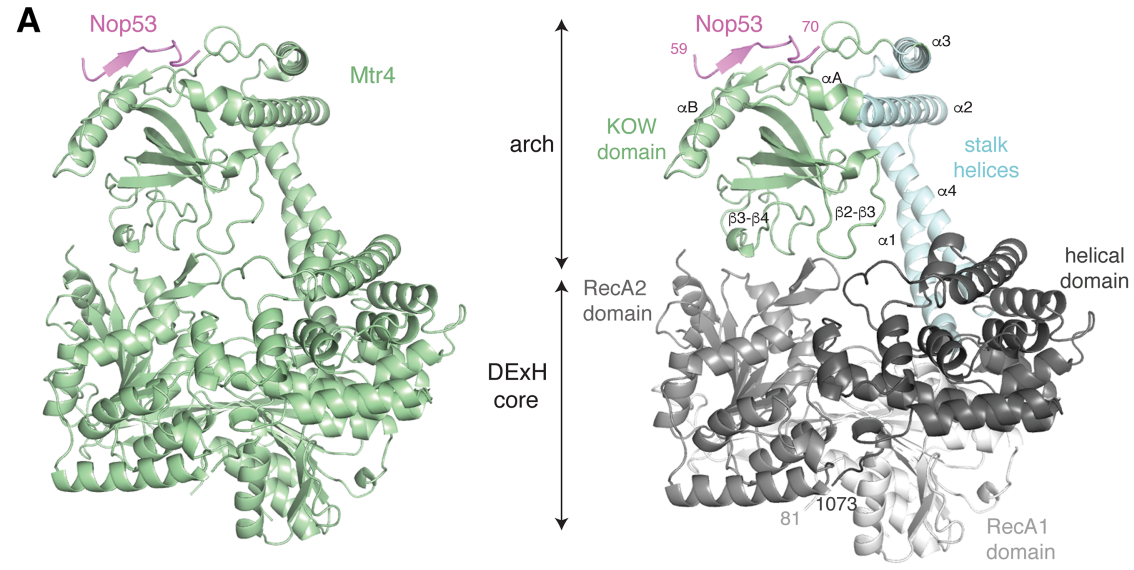

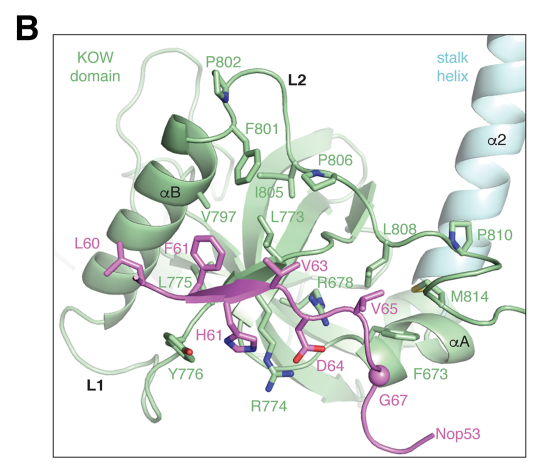

D

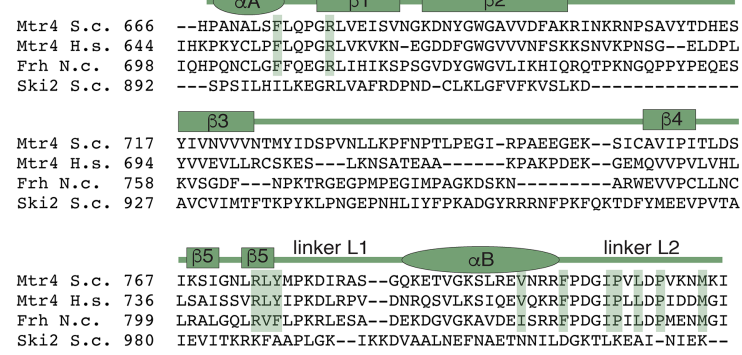

C

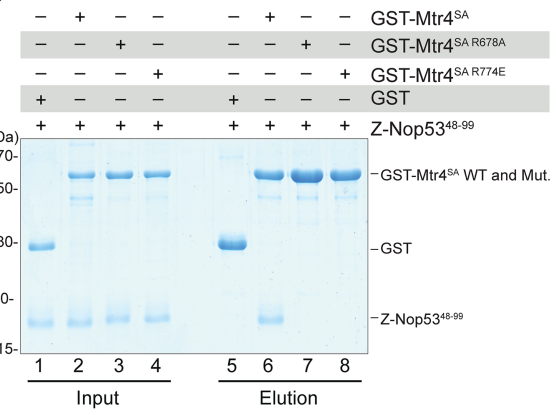

E

Nop53 S.C. 59 ALFHQDDVEGDEILK Nop53 H.s. 85 KLFFVDT-GSKEKG Nop53 N.c. 61 ELFAIDVKPDTEIT Utp18 S.c. 83 QLFFVDDGGNEDSQ Utp18 N.c.115 ALFAFD-TGVPGNK

FIGURE 2. Crystal structure of S. cerevisiae Mtr4- $\Delta \mathrm{N}$ bound to the Nop53 AIM. (A) On the left is the overall structure of Mtr4- $\Delta \mathrm{N}$ (green) and the Nop53 AIM motif (pink). On the right is a more detailed snapshot where Mtr4 is in the same orientation but colored by domains (as in the schematics in Fig. 1A). The RecA1, RecA2, and helical domains of the DExH core are colored from lighter to darker shades of gray. The stalk helices and KOW domain of the arch are in cyan and green, respectively. Secondary structure elements discussed in the text are highlighted. (B) Zoom-in view of the interactions between Nop53 and the Mtr4 KOW domain. The domains are colored as in Figure 2A, right panel, and viewed after a $90^{\circ}$ rotation around a horizontal axis with respect to the view in Figure 2A. Residues discussed in the text are highlighted and labeled. $(C)$ Protein coprecipitations by GST pull-down assays. GST-tagged yeast Mtr4 short arch (GST-Mtr4 ${ }^{\mathrm{SA}}$ ), and mutants were purified and mixed with purified Z-tagged Nop53 ${ }^{48-99}$. Pulldown assays were carried out using GSH-Sepharose beads in a buffer containing $150 \mathrm{mM} \mathrm{NaCl}$. The Coomassie-stained 16\% SDS-PAGE gels show the input (lanes 1-4) and the pulled-down protein precipitates (lanes 5-8). (D) Sequence alignment of the Mtr4 KOW domain from S. cerevisiae (S.c.), H. sapiens (H.s.), and the N. crassa (N.c.) ortholog FRH. The alignment includes the related cytoplasmic helicase Ski2 from S. cerevisiae. Secondary structure elements are shown above the sequence alignment with $\alpha$-helices indicated by an ellipse and $\beta$-strands by a rectangle. (E) Sequence alignment of the arch-interacting motifs (AIM) of Nop53 and Utp18 from S. cerevisiae (S.c.), H. sapiens (H.s.), and the N. crassa (N.c.). Note: H.s. UTP18 does not contain an AIM and is therefore not shown.

In addition to binding AIM-containing proteins, the KOW domain of Mtr4 also binds structured RNAs, albeit with low affinity (Weir et al. 2010; Li et al. 2016). Recently, the cryo-EM structure of the related helicase Ski2 in complex with cytoplasmic $80 \mathrm{~S}$ ribosomes revealed that the KOWlike domain of Ski2 approaches the rRNA via a cluster of positively-charged residues at the top of the $\beta$-barrel (includ- ing Lys903 ${ }_{\text {Ski2 }}$ and Lys987 ${ }_{\text {Ski2 }}$ ) (Schmidt et al. 2016). Furthermore, the KOW domain of the E. coli ribosomal protein L24 binds the $23 \mathrm{~S}$ rRNA via a set of positively charged residues at a similar position of $\operatorname{Arg} 678_{\text {Mtr } 4}$ (e.g., Lys903 $3_{\text {Ski2 }}$ ) and $\operatorname{Arg} 774_{\text {Mtr } 4}$ (e.g., Lys987 ${ }_{\text {Ski2 }}$ ) (Weir et al. 2010). Thus, the KOW domains of Ski2 and L24 engage rRNAs at the surface used by Mtr4 to bind AIM-containing proteins, raising 
the question as to whether the interactions of Mtr4 with Nop53 and RNA are concomitant or mutually exclusive. To address this question, we used nuclear magnetic resonance (NMR), which in particular allows analysis of low-affinity interactions. First, we analyzed the secondary chemical shifts of the Mtr4 KOW domain in isolation, confirming that the secondary structure in solution determined by NMR is consistent with the crystal structure (Supplemental Fig. 3A). $\left\{{ }^{1} \mathrm{H}\right\}-{ }^{15} \mathrm{~N}$-heteronuclear NOE data indicate that the KOW domain is rigid except for the loop connecting $\beta$ strands 2 and 3 (Supplemental Fig. 3B). To analyze the binding interfaces with RNA and protein ligands, we carried out titration experiments using unlabeled ligands and a ${ }^{15} \mathrm{~N}$ la-

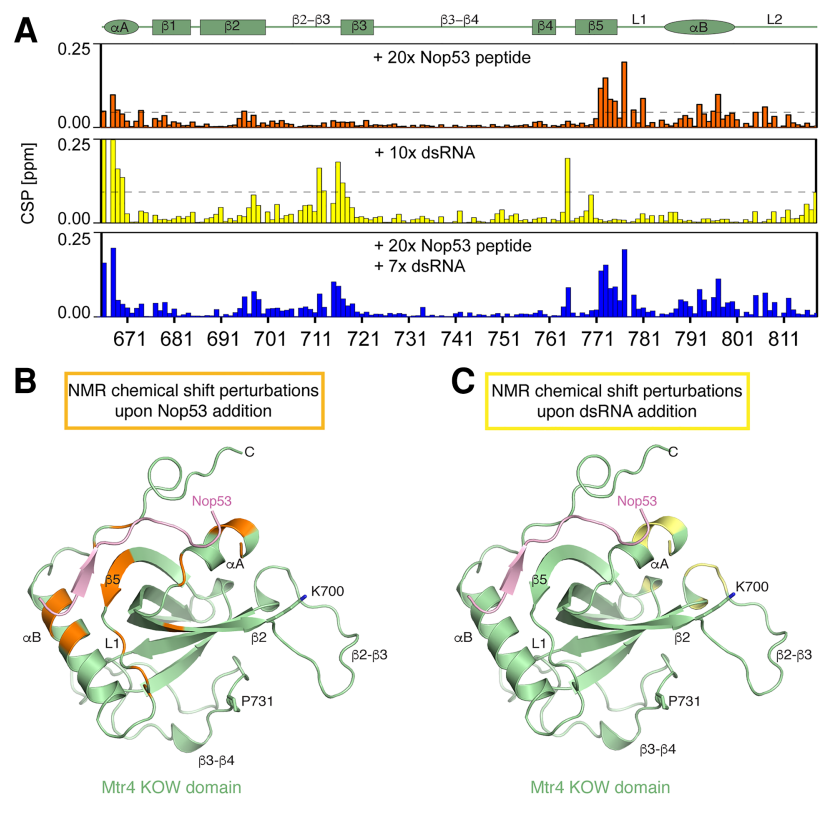

D

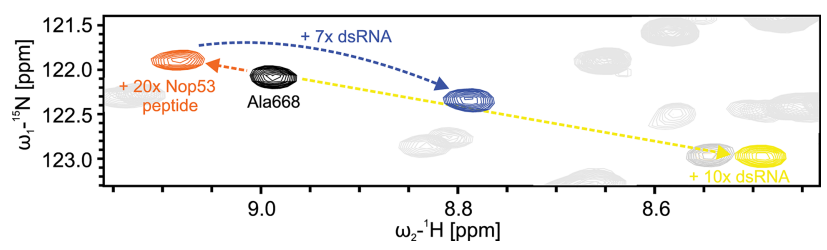

FIGURE 3. NMR studies of RNA and Nop53 binding. (A) NMR chemical shift perturbations (CSPs) for KOW domain titration with Nop53 peptide (orange), dsRNA (yellow), and both ligands simultaneously (blue). Note that in the presence of both ligands, CSPs correspond to the sum of the single ligand titrations. The secondary structure elements of the KOW domain are shown on top with $\alpha$-helices indicated by an ellipse and $\beta$-strands by a rectangle. The dashed horizontal lines indicate 1 SD unit of the shift for all residues. Only residues with a shift greater than 1 SD deviation are highlighted in $B$ and $C$. ( $B$ ) CSPs for Nop53 peptide titration plotted (in orange) onto the Mtr4-Nop53 crystal structure. (C) CSPs for dsRNA titration plotted (in yellow) onto the Mtr4-Nop53 crystal structure. Two residues previously shown to affect RNA-binding when mutated (K700N and P731S [Li et al. 2016]) are highlighted. (D) Zoomed view of ${ }^{1} \mathrm{H},{ }^{15} \mathrm{~N}-\mathrm{HSQC}$ spectra of free KOW (black) and with either (orange and yellow) or both ligands (blue). The chemical shifts appear additive with respect to the two individual ligand titration. beled Mtr4 KOW sample (Supplemental Fig. 4A-D). Chemical shift perturbations, measured upon addition of a Nop53 peptide containing the Mtr4-binding motif, revealed strong effects in the linker $\beta 5$ and L1 and the $\alpha \mathrm{B}$ helix, at the top of the KOW domain, consistent with the atomic model determined by crystallography (Fig. 3B). These structural elements were not significantly affected upon titrations with structured RNAs (either dsRNA or tRNA), which instead resulted in changes clustered in particular at the second half of strand $\beta 2$ and at the $\beta 2-\beta 3$ loop, a positively charged loop at the bottom of the $\beta$-barrel (Fig. 3C). Interestingly, two mutants (K700N and P731S) that had been previously identified from a dominant-negative screen in yeast and shown to affect RNA binding in vitro ( $\mathrm{Li}$ et al. 2016) are located in the vicinity of the RNA-binding residues identified by NMR (Fig. 3C). When titrating the dsRNA and the Nop53 peptide together, the CSPs observed were additive and reflected the sum of the individual titrations (Fig. 3D). This indicates that peptide and RNA can simultaneously bind to Mtr4 KOW and that the binding sites do not overlap.

Altogether, this study showed that the Mtr4 arch can bind AIM-containing proteins and structured RNAs simultaneously using adjacent surfaces on the KOW domain, indicating that the nuclear exosome helicase can in principle bind a preribosomal protein and preribosomal RNA during the processing of the ribosomal particles. Although the interacting surfaces appear to differ in detail, the equivalent domain of Ski2 docks onto the small ribosomal subunit of cytoplasmic ribosomes and binds a structured region of the $18 \mathrm{~S}$ rRNA and to the S3 and S20 proteins (Schmidt et al. 2016). Thus, Mtr4 and Ski2 have embedded in their arch domain an RNP-binding module capable of recognizing ribosomal RNPs. The structural similarity between the KOW-like domains in the arch of exosome-associated helicases and the KOW domain of ribosomal proteins might indeed reflect an evolutionary related origin.

\section{MATERIALS AND METHODS}

\section{Protein expression and purification}

Yeast Mtr4- $\Delta \mathrm{N}$ (residues 81-1073) was expressed as a His-GSTtagged fusion protein in $\mathrm{BL} 21(\mathrm{DE} 3)$ at $18^{\circ} \mathrm{C}$ overnight and purified as described in Weir et al. (2010). Briefly, Mtr4- $\Delta \mathrm{N}$ was purified via a Ni-nitrilotriacetate (NTA) affinity step and ion-exchange chromatography using a heparin column. The His-GST-tag was cleaved by His-tagged 3C protease. The cleaved tag and the $3 \mathrm{C}$ protease were removed by an additional Ni-nitrilotriacetate (NTA) affinity step. In the final purification step, the protein was subjected to size-exclusion chromatography on a Superdex200 in $20 \mathrm{mM}$ Hepes/NaOH pH 7.5, $150 \mathrm{mM} \mathrm{NaCl}, 10 \%$ (v/v) glycerol, $2 \mathrm{mM}$ DTT.

Yeast Nop53 fragments were expressed as His-Ztag-fusion protein (Nop53 residues 48-99) or His-Trx-fusion protein (Nop53 residues 58-91) in $\mathrm{BL} 21(\mathrm{DE} 3)$ at $18^{\circ} \mathrm{C}$ overnight. Nop53 fragments were purified via a Ni-nitrilotriacetate (NTA) affinity 
step. The tags were cleaved by His-tagged 3C protease. The cleaved tag and the $3 \mathrm{C}$ protease were removed by an additional Ni-nitrilotriacetate (NTA) affinity step. In the final purification step, the protein was subjected to size-exclusion chromatography on a Superdex75 in $20 \mathrm{mM}$ Hepes/ $\mathrm{NaOH}$ pH 7.5, $250 \mathrm{mM}$ $\mathrm{NaCl}, 2 \mathrm{mM}$ DTT.

\section{Isothermal titration calorimetry}

ITC experiments were carried out using a VP-ITC Isothermal titration calorimeter from Microcal. All samples were extensively dialysed against a buffer containing $20 \mathrm{mM}$ Hepes/ $\mathrm{NaOH} \mathrm{pH} 7.5$, $150 \mathrm{mM} \mathrm{NaCl}$, and $0.25 \mathrm{mM}$ TCEP. For Nop53: Mtr4- $\Delta \mathrm{N}$ (the reactant) samples were concentrated to $30 \mu \mathrm{M}$ and Nop53 prot (the injectant) to $400 \mu \mathrm{M}$. For Utp18: Mtr4- $\Delta \mathrm{N}$ (the reactant) samples were concentrated to $43 \mu \mathrm{M}$ and Utp18 $8_{\text {prot }}$ (the injectant) to $550 \mu \mathrm{M}$. Titrations were carried out at $25^{\circ} \mathrm{C}$ with $10 \mu \mathrm{L}$ of the injectant added to $1.4 \mathrm{~mL}$ of reactant cell solution. All data were processed and curves fitted using Origin 5.0.

\section{Pull-down assays}

For interaction studies the respective combination of proteins $80 \mu \mathrm{M}$ of bait protein (GST-Mtr4 ${ }^{\text {SA }}$, residues 638-842, wild-type and mutants) was preincubated with $100 \mu \mathrm{M}$ of prey (Z-tagged Nop53, residues 48-99) in a buffer containing $20 \mathrm{mM}$ Hepes/ $\mathrm{NaOH} \mathrm{pH}$ 7.5, $150 \mathrm{mM} \mathrm{NaCl}, 5 \mathrm{mM}$ DTT, and $0.05 \%(\mathrm{v} / \mathrm{v}) \mathrm{NP}-40$ for $1 \mathrm{~h}$ at $0^{\circ} \mathrm{C}$. Then the sample was incubated with $\mathrm{GSH}$ Sepharose (GE Healthcare) for $2 \mathrm{~h}$ at $4^{\circ} \mathrm{C}$, washed three times with the same buffer, and eluted in $20 \mathrm{mM}$ Tris/ $\mathrm{HCl} \mathrm{pH} \mathrm{7.5,} 150 \mathrm{mM}$ $\mathrm{NaCl}, 2 \mathrm{mM}$ DTT, $0.01 \%$ (v/v) NP-40 and $30 \mathrm{mM}$ reduced gluthathione. Input and pull-down fractions were analyzed on denaturing $16 \%$ SDS-PAGE and visualized by staining with Instant Blue (Expedeon).

\section{Crystallization and structure determination}

Mtr4- $\Delta \mathrm{N}$ was mixed with 1.5 molar excess of Nop53 $3_{\text {prot }}$ and the buffer was exchanged to $20 \mathrm{mM}$ Hepes/NaOH pH 7.5, $150 \mathrm{mM}$ ammonium sulfate, $2 \mathrm{mM}$ DTT. Just before crystallization $2 \mathrm{mM}$ $\mathrm{MgCl}_{2}$ and $1 \mathrm{mM}$ ADP were added. Crystallization trials were performed using a vapour diffusion setup. The best diffracting crystals were obtained at a concentration of $12 \mathrm{mg} / \mathrm{mL}$ at $12^{\circ} \mathrm{C}$ in $20 \%$ PEG 6000, $200 \mathrm{mM}$ lithium citrate. The crystals were cryoprotected with the reservoir solution supplemented with $20 \%$ (v/v) ethylene glycol prior to data collection at $100 \mathrm{~K}$. All diffraction data were collected at the X06DA (PXIII) beamline of the Swiss Light Source. Data processing and scaling was performed using the XDS package (Kabsch 2010). Crystals belong to the monoclinic spacegroup $\mathrm{P} 2_{1}$, contained two complexes in the asymmetric unit, and diffracted to $3.2 \AA$ resolution. The structure of the Mtr4- $\Delta \mathrm{N}-\mathrm{Nop} 53_{\text {prot }}$ complex was solved by molecular replacement with Phaser (McCoy et al. 2007) using the coordinates of DExH core (residues 80-613 and 876-1073) and the KOW-domain (residues 671-804) of Mtr4 (Weir et al. 2010) (PDB 2XGJ) as search models. The model was manually completed with COOT (Emsley et al. 2010) and refined with PHENIX (Adams et al. 2010).

\section{RNA sample preparation}

Yeast phenylalanine tRNA was purchased from Sigma-Aldrich. The double-stranded RNA was transcribed in vitro using T7 polymerase as two individual strands (\#1: 5'-GGAGCUUUCAAAAUGAUCU CCUU-3', \#2: 5'-GGAGAUCAUUUUGAAAGCUCCUU-3') and purified by agarose gel electrophoresis and electro-elution. The two strands were mixed in equimolar amounts prior to measurements. Structural integrity for double-stranded and structured RNAs was confirmed by NMR spectroscopy.

\section{NMR spectroscopy}

For all NMR measurements $5 \% \mathrm{D}_{2} \mathrm{O}$ was added to the samples for locking. All spectra were recorded at $298 \mathrm{~K}$ on AVIII 600, AVIII 900, and AVIII 950 Bruker NMR spectrometers equipped with cryogenic triple resonance-gradient probes. For data processing, Topspin 3.5 was used while analysis was done with Sparky 3.115 (T.D. Goddard and D.G. Kneller, Sparky 3, University of California, San Francisco). HNCACB, HNCA, and HNcoCA experiments (Sattler et al. 1999) were recorded for protein backbone assignment as well as hetNOE data on an $\sim 200 \mu \mathrm{M}{ }^{15} \mathrm{~N}^{13} \mathrm{C}$ labeled Mtr4-KOW sample. RNAs were analyzed using $1 \mathrm{D}$ and ${ }^{1} \mathrm{H},{ }^{1} \mathrm{H}-\mathrm{NOESY}$ experiments. All samples were buffer exchanged prior to measurement to $20 \mathrm{mM}$ Hepes/ $\mathrm{NaOH}$ pH $6.5,150 \mathrm{mM} \mathrm{NaCl}, 2 \mathrm{mM} \beta$-mercaptoethanol and $5 \%(\mathrm{v} / \mathrm{v})$ glycerol. For titration experiments the protein concentration was adjusted to $15-35 \mu \mathrm{M}$ and titrated with RNAs and Nop53 peptide as follows: The ratios used for doublestranded RNA were 1:0, 1:2, 1:5, 1:10; for Phe-tRNA 1:0, 1:2, 1:5, 1:7; and for the peptide 1:0, 1:2, 1:5, 1:10, 1:20. The dsRNA was furthermore added in a 1:7 ratio to the KOW-Nop53 peptide complex sample. The chemical shift perturbations were calculated as CSP $(\mathrm{ppm})=\left[(\Delta \mathrm{H})^{2}+((\Delta \mathrm{N}) / 6.51)^{2}\right]^{0.5}$.

\section{DATA DEPOSITION}

The coordinates have been deposited in the Protein Data Bank with the accession codes 5OOQ.

\section{SUPPLEMENTAL MATERIAL}

Supplemental material is available for this article.

\section{ACKNOWLEDGMENTS}

We thank Karina Valer-Saldaña and Sabine Pleyer at the MPIMartinsried crystallization facility for robotic crystal screening and optimization setups. We also thank the staff of the PX beamlines of the SLS synchrotron for assistance in data collection. This study was supported by the Max Planck Gesellschaft, the European Commission (European Research Council Advanced Investigator Grant 294371), and the Deutsche Forschungsgemeinschaft (SFB646, SFB1035, GRK1721, FOR1680 to E.C., and SFB1035 and GRK1721 to M.S.). This work was supported by the Cluster of Excellence EXC114 (to E.C. and M.S.)

Author contributions: S.F., M.T., E.H., and E.C. initiated the project; S.F. and J.B. performed crystallographic data collection in the laboratory of E.C.; S.F. solved and refined the crystal structure and performed the biochemical work in the laboratory of E.C.; J.T. 
carried out the NMR work in the laboratory of M.S.; S.F. J.T., M.S., and E.C. wrote the manuscript.

Received July 9, 2017; accepted September 5, 2017.

\section{REFERENCES}

Adams PD, Afonine PV, Bunkóczi G, Chen VB, Davis IW, Echols N, Headd JJ, Hung LW, Kapral GJ, Grosse-Kunstleve RW, et al. 2010. PHENIX: a comprehensive Python-based system for macromolecular structure solution. Acta Crystallogr D Biol Crystallogr 66: 213-221.

Allmang C, Kufel J, Chanfreau G, Mitchell P, Petfalski E, Tollervey D. 1999. Functions of the exosome in rRNA, snoRNA and snRNA synthesis. EMBO J 18: 5399-5410.

Allmang C, Mitchell P, Petfalski E, Tollervey D. 2000. Degradation of ribosomal RNA precursors by the exosome. Nucleic Acids Res 28: 1684-1691.

Araki Y, Takahashi S, Kobayashi T, Kajiho H, Hoshino S, Katada T. 2001. Ski7p G protein interacts with the exosome and the Ski complex for $3^{\prime}$-to-5' mRNA decay in yeast. EMBO J 20: 4684-4693.

Bernstein KA, Gallagher JEG, Mitchell BM, Granneman S, Baserga SJ. 2004. The small-subunit processome is a ribosome assembly intermediate. Eukaryot Cell 3: 1619-1626.

Briggs MW. 1998. Rrp6p, the yeast homologue of the human PM-Scl $100-\mathrm{kDa}$ autoantigen, is essential for efficient $5.8 \mathrm{~S}$ rRNA $3^{\prime}$ end formation. J Biol Chem 273: 13255-13263.

Brown JT, Bai X, Johnson AW. 2000. The yeast antiviral proteins Ski2p, Ski3p, and Ski8p exist as a complex in vivo. RNA 6: 449-457.

Butler JS, Mitchell P. 2011. Rrp6, rrp47 and cofactors of the nuclear exosome. Adv Exp Med Biol 702: 91-104.

Chlebowski A, Lubas M, Jensen TH, Dziembowski A. 2013. RNA decay machines: the exosome. Biochim Biophys Acta 1829: 552-560.

Emsley P, Lohkamp B, Scott WG, Cowtan K. 2010. Features and development of Coot. Acta Crystallogr D Biol Crystallogr 66: 486-501.

Falk S, Weir JR, Hentschel J, Reichelt P, Bonneau F, Conti E. 2014. The molecular architecture of the TRAMP complex reveals the organization and interplay of its two catalytic activities. Mol Cell 55: 856-867.

Graille M, Séraphin B. 2012. Surveillance pathways rescuing eukaryotic ribosomes lost in translation. Nat Rev Mol Cell Biol 13: 727-735.

Granato DC, Gonzales FA, Luz JS, Cassiola F, Machado-Santelli GM, Oliveira CC. 2005. Nop53p, an essential nucleolar protein that interacts with Nop17p and Nip7p, is required for pre-rRNA processing in Saccharomyces cerevisiae. FEBS J 272: 4450-4463.

Granato DC, Machado-Santelli GM, Oliveira CC. 2008. Nop53p interacts with $5.8 \mathrm{~S}$ rRNA co-transcriptionally, and regulates processing of pre-rRNA by the exosome. FEBS J 275: 4164-4178.

Halbach F, Rode M, Conti E. 2012. The crystal structure of S. cerevisiae Ski2, a DExH helicase associated with the cytoplasmic functions of the exosome. RNA 18: 124-134.

Halbach F, Reichelt P, Rode M, Conti E. 2013. The yeast ski complex: crystal structure and RNA channeling to the exosome complex. Cell 154: 814-826.

Henras AK, Plisson-Chastang C, O’Donohue MF, Chakraborty A, Gleizes PE. 2015. An overview of pre-ribosomal RNA processing in eukaryotes. Wiley Interdiscip Rev RNA 6: 225-242.

Jackson RN, Klauer AA, Hintze BJ, Robinson H, van Hoof A, Johnson SJ. 2010. The crystal structure of Mtr4 reveals a novel arch domain required for rRNA processing. EMBO J 29: 2205-2216.

Johnson SJ, Jackson RN. 2013. Ski2-like RNA helicase structures: common themes and complex assemblies. RNA Biol 10: 33-43.

Kabsch W. 2010. Integration, scaling, space-group assignment and postrefinement. Acta Crystallogr D Biol Crystallogr 66: 133-144.

Kilchert C, Wittmann S, Vasiljeva L. 2016. The regulation and functions of the nuclear RNA exosome complex. Nat Rev Mol Cell Biol 17: 227-239.

Klauer AA, van Hoof A. 2012. Genetic interactions suggest multiple distinct roles of the arch and core helicase domains of Mtr4 in Rrp6 and exosome function. Nucleic Acids Res 41: 533-541.
Kowalinski E, Kögel A, Ebert J, Reichelt P, Stegmann E, Habermann B, Conti E. 2016. Structure of a cytoplasmic 11-subunit RNA exosome complex. Mol Cell 63: 125-134.

Kyrpides NC, Woese CR, Ouzounis CA. 1996. KOW: a novel motif linking a bacterial transcription factor with ribosomal proteins. Trends Biochem Sci 21: 425-426.

Li Y, Burclaff J, Anderson JT. 2016. Mutations in Mtr4 structural domains reveal their important role in regulating tRNA $_{\mathrm{i}}^{\text {Met }}$ turnover in Saccharomyces cerevisiae and Mtr4p enzymatic activities in vitro. PLoS One 11: e0148090.

Makino DL, Baumgärtner M, Conti E. 2013a. Crystal structure of an RNAbound 11-subunit eukaryotic exosome complex. Nature 495: 70-75.

Makino DL, Halbach F, Conti E. 2013b. The RNA exosome and proteasome: common principles of degradation control. Nat Rev Mol Cell Biol 14: 654-660.

Makino DL, Schuch B, Stegmann E, Baumgärtner M, Basquin C, Conti E. 2015. RNA degradation paths in a 12-subunit nuclear exosome complex. Nature 524: 54-58.

McCoy AJ, Grosse-Kunstleve RW, Adams PD, Winn MD, Storoni LC, Read RJ. 2007. Phaser crystallographic software. J Appl Crystallogr 40: $658-674$.

Mitchell P, Petfalski E, Shevchenko A, Mann M, Tollervey D. 1997. The exosome: a conserved eukaryotic RNA processing complex containing multiple $3^{\prime} \rightarrow>5^{\prime}$ exoribonucleases. Cell 91: 457-466.

Nissan TA, Bassler J, Petfalski E, Tollervey D, Hurt E. 2002. 60S pre-ribosome formation viewed from assembly in the nucleolus until export to the cytoplasm. EMBO J 21: 5539-5547.

Ozgur S, Buchwald G, Falk S, Chakrabarti S, Prabu JR, Conti E. 2015. The conformational plasticity of eukaryotic RNA-dependent ATPases. FEBS J 282: 850-863.

Sattler M, Schleucher J, Griesinger C. 1999. Heteronuclear multidimensional NMR experiments for the structure determination of proteins in solution employing pulsed field gradients. Prog Nucl Magn Reson Spectrosc 34: 93-158.

Schaeffer D, Clark A, Klauer AA, Tsanova B, van Hoof A. 2011. Functions of the cytoplasmic exosome. Adv Exp Med Biol 702: 79-90.

Schilders G, Raijmakers R, Raats JMH, Pruijn GJM. 2005. MPP6 is an exosome-associated RNA-binding protein involved in 5.8S rRNA maturation. Nucleic Acids Res 33: 6795-6804.

Schilders G, Egberts WV, Raijmakers R, Pruijn GJM. 2007. C1D is a major autoantibody target in patients with the polymyositis-scleroderma overlap syndrome. Arthritis Rheum 56: 2449-2454.

Schmidt C, Kowalinski E, Shanmuganathan V, Defenouillère Q, Braunger K, Heuer A, Pech M, Namane A, Berninghausen O, Fromont-Racine M, et al. 2016. The cryo-EM structure of a ribosome-Ski2-Ski3-Ski8 helicase complex. Science 354: 1431-1433.

Schuch B, Feigenbutz M, Makino DL, Falk S, Basquin C, Mitchell P, Conti E. 2014. The exosome-binding factors Rrp6 and Rrp47 form a composite surface for recruiting the Mtr4 helicase. EMBO J 33: 2828-2846.

Shi M, Collett M, Loros JJ, Dunlap JC. 2010. FRQ-interacting RNA helicase mediates negative and positive feedback in the Neurospora circadian clock. Genetics 184: 351-361.

Shoemaker CJ, Green R. 2012. Translation drives mRNA quality control. Nat Struct Mol Biol 19: 594-601.

Sloan KE, Schneider C, Watkins NJ. 2012. Comparison of the yeast and human nuclear exosome complexes. Biochem Soc Trans 40: 850-855.

Thoms M, Thomson E, Bassler J, Gnädig M, Griesel S, Hurt E. 2015. The exosome is recruited to RNA substrates through specific adaptor proteins. Cell 162: 1029-1038.

Thomson E, Tollervey D. 2005. Nop53p is required for late 60 S ribosome subunit maturation and nuclear export in yeast. RNA 11: 1215-1224.

Thomson E, Tollervey D. 2010. The final step in 5.8S rRNA processing is cytoplasmic in Saccharomyces cerevisiae. Mol Cell Biol 30: 976-984.

Thomson E, Ferreira-Cerca S, Hurt E. 2013. Eukaryotic ribosome biogenesis at a glance. J Cell Sci 126: 4815-4821.

Turowski TW, Tollervey D. 2015. Cotranscriptional events in eukaryotic ribosome synthesis. Wiley Interdiscip Rev RNA 6: 129-139. 


\section{S. cerevisiae Mtr4-Nop53 structure}

Wasmuth EV, Januszyk K, Lima CD. 2014. Structure of an Rrp6-RNA exosome complex bound to poly(A) RNA. Nature 511: 435-439.

Weir JR, Bonneau F, Hentschel J, Conti E. 2010. Structural analysis reveals the characteristic features of Mtr4, a DExH helicase involved in nuclear RNA processing and surveillance. Proc Natl Acad Sci 107: 12139-12144.

Wu S, Tutuncuoglu B, Yan K, Brown H, Zhang Y, Tan D, Gamalinda M, Yuan Y, Li Z, Jakovljevic J, et al. 2016. Diverse roles of assembly fac- tors revealed by structures of late nuclear pre-60S ribosomes. Nature 534: 133-137.

Zinder JC, Lima CD. 2017. Targeting RNA for processing or destruction by the eukaryotic RNA exosome and its cofactors. Genes Dev 31: $88-100$.

Zinder JC, Wasmuth EV, Lima CD. 2016. Nuclear RNA exosome at 3.1 $\AA$ reveals substrate specificities, RNA paths, and allosteric inhibition of Rrp44/Dis3. Mol Cell 64: 734-745. 

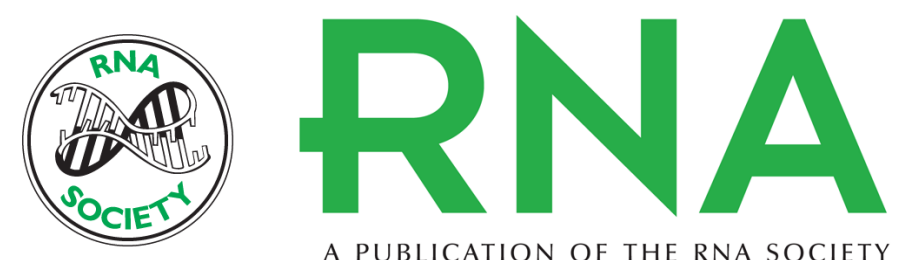

A PUBLICATION OF THE RNA SOCIETY

\section{Structural insights into the interaction of the nuclear exosome helicase Mtr4 with the preribosomal protein Nop53}

Sebastian Falk, Jan-Niklas Tants, Jerôme Basquin, et al.

RNA 2017 23: 1780-1787 originally published online September 7, 2017

Access the most recent version at doi:10.1261/rna.062901.117

\section{Supplemental http://rnajournal.cshlp.org/content/suppl/2017/09/07/rna.062901.117.DC1 \\ Material}

References This article cites 51 articles, 16 of which can be accessed free at: http://rnajournal.cshlp.org/content/23/12/1780.full.html\#ref-list-1

Open Access Freely available online through the RNA Open Access option.

Creative This article, published in $R N A$, is available under a Creative Commons License Commons (Attribution-NonCommercial 4.0 International), as described at License http://creativecommons.org/licenses/by-nc/4.0/.

Email Alerting Receive free email alerts when new articles cite this article - sign up in the box at the Service top right corner of the article or click here.

\section{|||||||| Providing Precise Solutions for your research.}

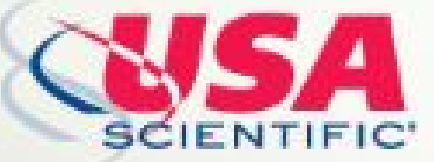

To subscribe to $R N A$ go to:

http://rnajournal.cshlp.org/subscriptions

(C) 2017 Falk et al.; Published by Cold Spring Harbor Laboratory Press for the RNA Society 